\title{
Diabetes During the Fasting Month of Ramadan: Is Telemedicine as Efficient as Conventional Follow-Up? Results from a Moroccan Comparative Study
}

\author{
Imane Motaib iD ${ }^{\prime}$ \\ Saloua Elamari \\ Mohamed Khalis (iD ${ }^{2}$ \\ Meryem Drissi Oudghiri' \\ Soukaina Laidi ${ }^{1}$ \\ Asma Chadli \\ 'Department of Endocrinology \\ Diabetology Metabolic Disease and \\ Nutrition, Mohammed VI University of \\ Health Sciences (UM6SS), Casablanca, \\ Morocco; ${ }^{2}$ International School of Public \\ Health, Mohammed VI University of \\ Health Sciences, Casablanca, Morocco
}

\begin{abstract}
Aim: During the COVID-19 pandemic, access to health care was affected by the lockdown period. To overcome this situation, telemedicine is an alternative to conventional follow-up for patients with diabetes during the fasting month of Ramadan. The aim of this study is to compare the effectiveness of telemedicine consultation of diabetic patients during Ramadan compared with conventional follow-up.

Methods: This comparative cross-sectional study conducted in the Sheikh Khalifa Ibn Zaid Hospital of Casablanca, Morocco, included diabetic patients followed up by conventional consultation in 2019 Ramadan and by telemedicine in 2020 Ramadan. For each patient and in both Ramadans (2019 and 2020), we have conducted a pre-Ramadan assessment, screening for acute diabetic complications during Ramadan and an evaluation of weight and glycated hemoglobin of patients, after Ramadan. We compared the occurrence of acute complications and the variation of metabolic parameters of patients in Ramadan 2020 with their results in Ramadan 2019.

Results: In this study, we included 61 patients. In Ramadan 2020, compared with Ramadan 2019 , there was no significant difference in terms of hypoglycemia ( $18.03 \%$ versus $32.78 \%$, $\mathrm{p}=0.09)$, minor hyperglycemia $(13.1 \%$ versus $11.47 \%, \mathrm{p}=0.35)$ and major hyperglycemia or ketoacidosis $(3.27 \%$ versus $6.55 \%, \mathrm{p}=0.19)$. Fasting was interrupted in $8.19 \%$ versus $11.47 \%(\mathrm{p}=0.012)$. There were no significant variations of weight $(+0.62$ versus $-0.77 ; \mathrm{p}=$ $0.09)$. In term of variation of glycated hemoglobin, there was a significant different between Ramadan 2020 and Ramadan 2019 ( -0.36 versus -0.61 in 2019, p<0.05).

Conclusion: Despite comparable results in terms of weight change and hypoglycemia, our study showed that telemedicine follow-up in patients with diabetes during Ramadan did not provide as effective glycemic control as conventional monitoring.
\end{abstract}

Keywords: Ramadan, diabetes, COVID-19, telemedicine

\section{Introduction}

Fasting during Ramadan is one of the five pillars of Islam. It consists of refraining from eating and drinking from sunrise to sunset. Despite exemptions for individuals with chronic medical conditions such as diabetes, many diabetic patients fast during Ramadan for cultural and faith reasons. ${ }^{1}$

The management of diabetes during the fasting month of Ramadan is a challenge for healthcare professionals, because of the risk of acute

\footnotetext{
Correspondence: Imane Motaib Faculty of Medicine, Mohammed VI University of Health Sciences (UM6SS), Casablanca, 82403, Morocco Email imanemotaib@gmail.com; imotaib@um6ss.ma
} 
complications associated with fasting. To minimize this risk, well-defined recommendations for managing diabetes during the month of Ramadan have been elaborated. ${ }^{2}$ Indeed, for diabetic patients who decide to fast, it is recommended to perform a pre-Ramadan consultation, to assess the fasting related risk, to educate patients for diabetes self-management, and to adjust treatment regimen. In addition, diabetic patients who do not fast during the month of Ramadan are also at risk of unbalancing their diabetes due to changes in dietary habits and in meal times during this month.

The 2020 Ramadan started from April 24 and May 24, 2020, and it coincided with the COVID-19 pandemic. The World Health Organization (WHO) declared on March 11, 2020, the 2019 coronavirus disease as a global pandemic. ${ }^{3}$ To stop the spread of coronavirus in Morocco, authorities imposed a total lockdown from March 16 to June 10, 2020. This situation hindered access to health care, limited face-to-face visits in hospitals and threatened the follow-up of diabetic patients during Ramadan.

To overcome this situation, telemedicine appeared to us as a feasible and structured alternative to diabetic patients face to face follow-up during Ramadan in the context of the COVID-19 pandemic. Even though the use of telemedicine in the monitoring of diabetic patients during Ramadan has been reported in many studies, ${ }^{4,5}$ very few authors evaluated the effectiveness of telemedicine follow-up in comparison with conventional follow-up during Ramadan, and fewer investigated this aspect in the context of the COVID-19 pandemic.

In the present study we aimed to compare the effectiveness of telemedicine consultation for diabetic patients followed-up in Cheikh Khalifa Ibn Zaid Hospital of Casablanca, Morocco, during Ramadan 2020 with conventional follow-up realized for these same patients in 2019 . Our hypothesis is that telemedicine follow-up is as efficient as conventional consultation.

\section{Materials and Methods Study Design}

This was a comparative cross-sectional study conducted in the Cheikh Khalifa Ibn Zaid Hospital of Casablanca, Morocco.

\section{Study Population}

In this study, we included patients with type 2 diabetes, from the department of endocrinology and diabetology of the Cheikh Khalifa Ibn Zaid Hospital of Casablanca, followed-up by conventional consultation in Ramadan 2019 and by telemedicine in 2020 Ramadan.

We included patients with diabetes aged above 18 years old already followed up during Ramadan 2019 who accepted to be followed up during Ramadan 2020 by telemedicine. We included all patients with diabetes whether they fast or not. Patients who did not fully complete the follow-up in both Ramadans were excluded in this study.

\section{Data Collection}

The study was conducted in three phases: the first phase (2 weeks before Ramadan), the second phase (the second week of Ramadan), and the third phase ( 2 weeks after Ramadan). For 2019, the data was collected from the patients' medical records, as we systematically follow-up all patients admitted in our department two weeks before, during and after Ramadan.

For each patient and in both Ramadans (2019 and 2020), and in order to recommend or not fasting for patients, we conducted a first pre-Ramadan consultation to determine the level of risk related to fasting. Patients were classified into three risk categories: low to moderate risk, high risk and very high risk, according to the International guidelines for management of diabetes during Ramadan, as represented in Box 1.,6 We also adjusted treatment, if necessary, for patients allowed to fast in Ramadan. Also in this first consultation, we provided an education on self-monitoring of blood glucose levels and what to do in cases of acute complications (hypo- or hyperglycemia). In addition, weight evaluation and a glycated hemoglobin test were performed for each patient. A second consultation was conducted during Ramadan to screen any acute diabetic complications and to assess the self-monitored blood glucose of patients. We defined acute complications as hypoglycemia (capillary blood glucose below $70 \mathrm{mg} / \mathrm{dl}$ ), minor hyperglycemia (capillary blood glucose above $180 \mathrm{mg} / \mathrm{dl}$ ), major hyperglycemia (capillary blood glucose above $300 \mathrm{mg} / \mathrm{dl}$ ) and ketoacidosis. A third consultation was performed after 
Box I Categories of Risk in Patients with Type 2 Diabetes Who Fast During Ramadan, According to International Guidelines

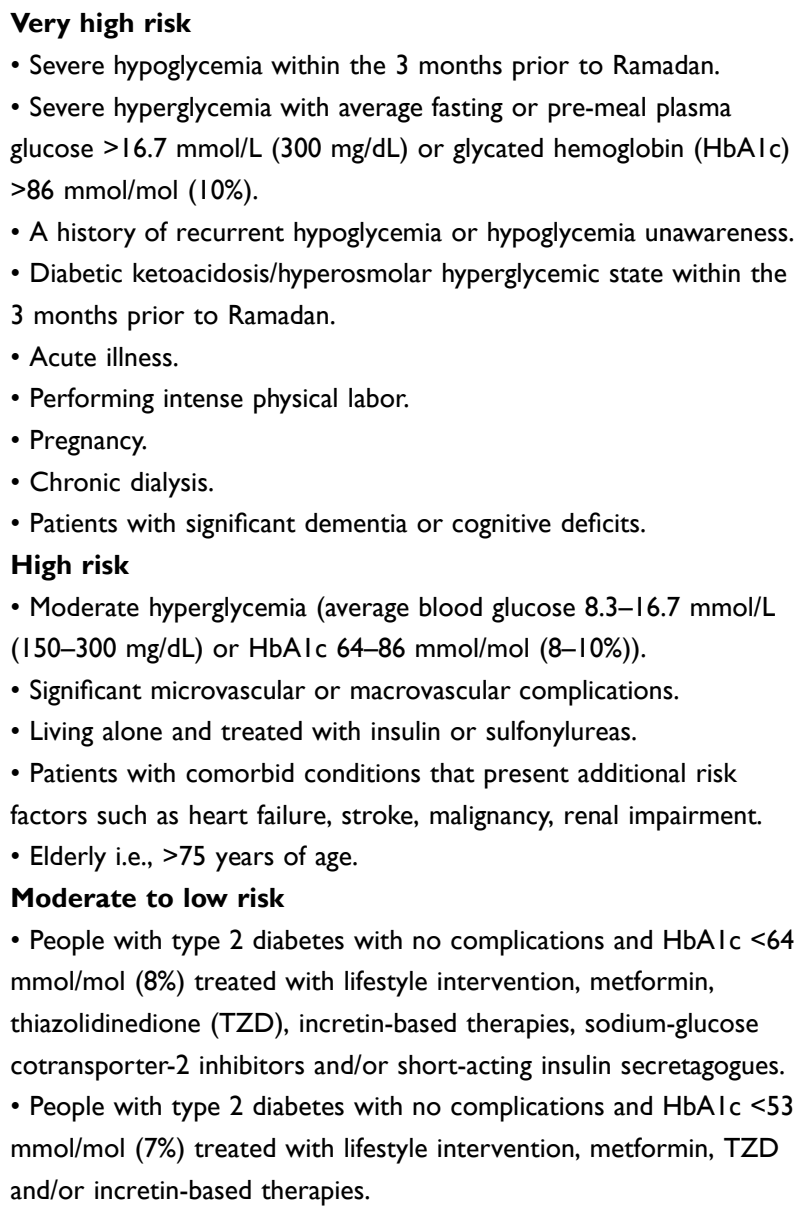

Note: Adapted from Ibrahim M, Davies MJ, Ahmad E, et al. Recommendations for management of diabetes during Ramadan: update 2020, applying the principles of the ADA/EASD consensus. BMJ Open Diab Res Care. 2020;8(I):e001248. doi:I0.1 136/ bmjdrc-2020-001248.

Ramadan to evaluate the weight of patients, and their glycated hemoglobin.

We used tele-education and tele-consultation as defined by the American Society of Telemedicine. ${ }^{7}$ For this study, we used VisioMedica Maroc $($ platform for telemedicine consultations.

To evaluate the effectiveness of telemedicine consultation, we compared the occurrence of acute diabetic complications, weight variation and glycemic control based on the variation in glycated hemoglobin (HbAlc) of patients in 2020 Ramadan and in 2019 Ramadan.

\section{Statistical Analysis}

For the descriptive analysis, we described continuous variables as medians with interquartile ranges (IQRs) and categorical variables as percentages and frequencies. The normality of continuous variables distribution was conducted using the Kolmogorov-Smirnov test. The McNemar test was used to examine categorical data and Student's test for paired-samples was performed to compare quantitative variables between Ramadan 2020 and Ramadan 2020.

The Wilcoxon test was used to analyze normally undistributed data. Statistical analyses were performed using SPSS 20.0.

All p-values were two-sided, and those $<0.05$ were considered statistically significant.

\section{Ethical Considerations}

The study was approved by the institutional ethics board of Cheikh Khalifa Ibn Zaid International University Hospital. Data confidentiality and patient anonymity were maintained at all stages of the study. We deleted patient-identifying information before analyzing the database. Informed consent was obtained for all patients prior to inclusion.

\section{Results}

A total of 61 patients were included in this study. The median (interquartile range) age of patients was 63 (57$69)$ years, and $55.7 \%$ of patients were male. All patients had type 2 diabetes; $32.7 \%$ were treated with non-insulin antidiabetic drugs, $34.4 \%$ with insulin injections, and $32.7 \%$ were under a combination therapy including insulin and oral antidiabetic drugs.

The stratification of risk related to fasting showed that $29.5 \%$ of patients had low to moderate risk, $37.7 \%$ had high risk and $32.8 \%$ had a very high risk. Of the participants, $41 \%$ fasted during Ramadan and $59 \%$ did not fast.

At the beginning of Ramadan 2020, the mean weight was $79.9 \mathrm{~kg}( \pm 13.18)$, with a mean body mass index of $28.37 \mathrm{~kg} / \mathrm{m}^{2}$ ( \pm 4.90$)$. The mean glycated hemoglobin was $8.07 \%( \pm 1.21)$. Characteristics of patients are represented in Table 1.

As shown in Table 2, in Ramadan 2020, compared with Ramadan 2019, there was no significant difference in terms of hypoglycemia (18.03\% versus $32.78 \%$ in $2019, \mathrm{p}=0.06$ ), minor hyperglycemia $(13.1 \%$ versus $11.47 \%$ in $2019, \mathrm{p}=$ $0.35)$ and major hyperglycemia $(3.27 \%$ versus $6.55 \%$ in $2019, \mathrm{p}=0.19)$. Fasting was interrupted by $8.19 \%$ of patients in 2020 versus $11.47 \%$ in 2019 ( $\mathrm{p}=0.62)$. There was no significant variation in weight $(+0.62$ in Ramadan 2020 versus -0.77 in Ramadan 2019; $p=0.09$ ). In terms of variation of glycated hemoglobin, there was a significant difference between Ramadan 2020 and Ramadan 2019 (-0.36 versus -0.61 in $2019, \mathrm{p}<0.05)$. 
Table I Characteristics of the Study Population $(N=6 I)$

\begin{tabular}{|c|c|}
\hline & Median (IQR) or n (\%) \\
\hline \multicolumn{2}{|l|}{ Demographics } \\
\hline Age, years median (IQR) & $63(57-69)$ \\
\hline \multicolumn{2}{|l|}{ Gender } \\
\hline Male & $34(55.7)$ \\
\hline Female & $27(44.3)$ \\
\hline \multicolumn{2}{|l|}{ Diabetes Medication } \\
\hline Non-insulin anti-diabetic & $20(32.78)$ \\
\hline Insulin therapy & $21(34.42)$ \\
\hline Combination therapy & $20(32.78)$ \\
\hline \multicolumn{2}{|l|}{ Risk Stratification } \\
\hline Low to Moderate & $38(29.5)$ \\
\hline High & $19(37.7)$ \\
\hline Very High & $18(32.8)$ \\
\hline \multicolumn{2}{|l|}{ Fasting Status } \\
\hline Fasting & $25(4 I)$ \\
\hline Not Fasting & $36(59)$ \\
\hline \multicolumn{2}{|c|}{ Anthropometric Characteristics } \\
\hline Weight (kg) & $79.9(13.18)$ \\
\hline BMI $\left(\mathrm{kg} / \mathrm{m}^{2}\right)$ & $28.37(4.90)$ \\
\hline HbAlc (\%) & $8.07(1.21)$ \\
\hline
\end{tabular}

Abbreviations: BMI, body Mass Index; HbAlc, glycated hemoglobin.

\section{Discussion}

Diabetes management during the month of Ramadan requires close follow-up and dynamic therapeutic adjustment to prevent acute diabetes-related complications. The

Table 2 Comparison of the Occurrence of Acute Complications, Fasting Interruption and Variations of Glycated Hemoglobin and Weight in Ramadan 2019 with Ramadan 2020

\begin{tabular}{|l|l|l|l|}
\hline & $\begin{array}{l}\text { Ramadan } \\
\mathbf{2 0 1 9} \mathbf{~ N}(\%)\end{array}$ & $\begin{array}{l}\text { Ramadan } \\
\mathbf{2 0 2 0} \mathbf{~ N}(\%)\end{array}$ & P values \\
\hline $\begin{array}{l}\text { Major hyperglycemia } \\
\text { or ketoacidosis }\end{array}$ & $4(6.55)$ & $3(4.9 I)$ & 0.19 \\
\hline Minor hyperglycemia & $7(I I .47)$ & $8(13.1)$ & 0.35 \\
\hline Hypoglycemia & $20(32.78)$ & $\mathrm{II}(18.03)$ & 0.06 \\
\hline Interruption of fasting & $7(\mathrm{II} .47)$ & $5(8.19)$ & 0.62 \\
\hline $\begin{array}{l}\text { Variation of HbAIc } \\
\text { (\%) }\end{array}$ & $-0.6 \mathrm{I}$ & -0.36 & $0.00 \mathrm{I}$ \\
\hline $\begin{array}{l}\text { Variation of weight } \\
\text { (kg) }\end{array}$ & -0.77 & +0.62 & 0.09 \\
\hline
\end{tabular}

main complications related to fasting in patients with diabetes are hyperglycemia, ketoacidosis, hypoglycemia, and dehydration, which increases the risk of thrombosis. ${ }^{8}$ Indeed, the EPIDIAR study demonstrated that the risk of hypoglycemia is 4.7 -fold higher for patients with type 1 diabetes, and 7.5-fold higher for type 2 diabetes mellitus patients during Ramadan. The CREED study also showed a higher incidence of hypoglycemia during Ramadan. ${ }^{8}$ Therefore, international guidelines recommend starting a pre-Ramadan assessment 4-8 weeks before Ramadan with the objective of stratifying the risk related to fasting, adjusting treatment and educating patients to prevent hypoglycemia, hyperglycemia, and weight gain., ${ }^{2,9}$ In addition, due to changes in meal schedules and eating habits, acute diabetic complications such as hypoglycemia and hyperglycemia may occur even if patients do not fast. Therefore, these patients should be followed up closely during the month of Ramadan.

The context of 2020 Ramadan is particular due to the COVID-19 pandemic. Governments imposed a lockdown period to stop the spread of the new coronavirus. Individuals with co-morbidities such as diabetes were advised to adhere to confinement drastically. Indeed, diabetes mellitus has been associated with severity and death in patients with COVID-19. The incidence of diabetes was higher in non-survivor patients than in survivor patients (31\% versus $14 \%) .{ }^{10}$ Also, the incidence of diabetes in the intensive care unit (ICU) patients was twofold higher than non-ICU patients. ${ }^{11}$

Ramadan 2020 came between April 24 and May 24, 2020 and coincided with the lockdown period in Morocco. During this period, access to health care was limited, which threatened the follow-up of patients with diabetes during Ramadan. To overcome this situation, telemedicine models are emerging as an alternative to traditional consultation.

Indeed, the use of telemedicine for the follow-up of patients with diabetes is widely studied. ${ }^{7}$ Several authors have demonstrated its effectiveness in improving diabetes patient care. A meta-analysis of 35 randomized controlled trials of telemedicine from China for patients with diabetes showed a reduction of $0.37 \%$ in $\mathrm{HbA} 1 \mathrm{c}$ in telemedicine groups compared with conventional follow-up controls. ${ }^{12}$ In another meta-analysis of 42 randomized controlled trials, the mean reduction in $\mathrm{HbAlc}$ was significantly higher in the telemedicine groups compared with usual care in managing diabetes, especially type 2 diabetes. ${ }^{13}$ Furthermore, some authors have been interested in telemedicine applied to the follow-up of diabetics during the 
month of Ramadan. Ulhaque et al. have trialled preRamadan diabetes education and treatment adjustment by using a station-based, 24-hour helpline service during the holy month of Ramadan. This study showed a significant decrease of glycated hemoglobin after Ramadan in type 2 patients with diabetes. $^{14}$

Our study showed that telemedicine follow-up of diabetic patients during Ramadan did not achieve better glycemic control than conventional follow-up (variations of glycated hemoglobin in 2019 were $-0.61 \%$ versus $-0.36 \%$ in 2020). This could be explained by the COVID context of our study. Confounding factors related to the pandemic and confinement context, such as a lack in physical activity and changes in eating behaviors during lockdown, could explain our findings. Indeed, many studies have demonstrated the impact of confinement on glycemic control of patients with diabetes. An Indian study showed an increase in blood glucose levels during the 3 first weeks of lockdown, $39.16 \%$ of patients developed hyperglycemia and required adjustment of treatment. ${ }^{15}$ In our study, there was no significant difference in terms of weight change, however, it should be noted that patients gained weight in $2020(+0.62)$, while they lost weight in 2019. This could be related to the confinement context.

Additionally, our study showed, that hypoglycemia was less prevalent in the telemedicine follow-up group $(18.03 \%$ versus $32.78 \%)$, but there was no significant difference $(p=0.06)$. Lee et al. determined the impact of a blood glucose telemonitoring program in type 2 diabetes mellitus patients fasting during Ramadan compared with the conventional self-monitoring method. ${ }^{4}$ The number of participants reporting hypoglycemia was significantly lower in the telemonitoring group [Odds ratio (OR): $0.186,95 \%$ confidence interval: $0.04-0.936 ; \mathrm{p}=0.04]$.

Our study has some limitations. First, is the relatively small number of patients included in the study. Second, we did not collect some factors that may influence glycemic control. Third, this was a single-centre study; further multicentre studies should be conducted to validate our results. However, our study has many strengths. This is the first study that has investigated the effectiveness of telemedicine follow-up in the context of the COVID-19 pandemic compared with a non-COVID situation. Second, we were able to make the comparison in the same patient sample in two Ramadans.

\section{Conclusion}

The management of diabetes during Ramadan in the COVID-19 pandemic context is an unprecedented situation. Our study showed that telemedicine follow-up of patients with diabetes during the month of Ramadan in the lockdown context, is not as effective as conventional follow-up in terms of glycemic control. However, telemedicine can be a supplement to conventional care during Ramadan, at least for monitoring weight and acute complications such as hypoglycemia. These results should be confirmed in a larger, multicenter study.

\section{Author Contributions}

All authors made substantial contributions to conception and design, acquisition of data, or analysis and interpretation of data; took part in drafting the article and revising it critically for important intellectual content; agreed to submit to the current journal; gave final approval of the version to be published; and agree to be accountable for all aspects of the work.

\section{Disclosure}

The authors report no conflicts of interest in this work.

\section{References}

1. Salti I, Benard E, Detournay B, et al. A population-based study of diabetes and its characteristics during the fasting month of Ramadan in 13 countries: results of the epidemiology of diabetes and Ramadan 1422/2001 (EPIDIAR) study. Diabetes Care. 2004;27(10):2306-2311. doi:10.2337/diacare.27.10.2306

2. Ibrahim M, Davies MJ, Ahmad E, et al. Recommendations for management of diabetes during Ramadan: update 2020, applying the principles of the ADA/EASD consensus. BMJ Open Diab Res Care. 2020;8(1):e001248. doi:10.1136/bmjdrc-2020-001248

3. World Health Organization. Rolling updates on coronavirus disease (COVID-19); 2020. Available from: https://www.who.int/emergencies/ diseases/novel-coronavirus-2019/events-as-they-happen. Accessed October 22, 2020

4. Lee JY, Wong CP, Tan CSS, Nasir NH, Lee SWH. Telemonitoring in fasting individuals with type 2 Diabetes Mellitus during Ramadan: a prospective, randomised controlled study. Sci Rep. 2017;7(1):10119. doi:10.1038/s41598-017-10564-y

5. Lee JY, Lee SWH, Nasir NH, How S, Tan CSS, Wong CP. Diabetes telemonitoring reduces the risk of hypoglycaemia during Ramadan: a pilot randomized controlled study. Diabet Med. 2015;32 (12):1658-1661. doi:10.1111/dme.12836

6. Ibrahim M, Abu Al Magd M, Annabi FA, et al. Recommendations for management of diabetes during Ramadan: update 2015. BMJ Open Diab Res Care. 2015;3(1):e000108. doi:10.1136/bmjdrc-2015-000108

7. Lee SW, Chan CK, Chua SS, Chaiyakunapruk N. Comparative effectiveness of telemedicine strategies on type 2 diabetes management: a systematic review and network meta-analysis. Sci Rep. 2017;7(1):1. doi:10.1038/s41598-017-12987-z

8. Babineaux SM, Toaima D, Boye KS, et al. Multi-country retrospective observational study of the management and outcomes of patients with Type 2 diabetes during Ramadan in 2010 (CREED). Diabet Med. 2015;32(6):819-828. doi:10.1111/dme.12685

9. Hassanein M, Al-Arouj M, Hamdy O, et al. Diabetes and Ramadan: practical guidelines. Diabetes Res Clin Pract. 2017;126:303-316. doi:10.1016/j.diabres.2017.03.003 
10. Zhou F, Yu T, Du R, et al. Clinical course and risk factors for mortality of adult inpatients with COVID-19 in Wuhan, China: a retrospective cohort study. Lancet. 2020;395(10229):1054-1062. doi:10.1016/S0140-6736(20)30566-3

11. Li B, Yang J, Zhao F, et al. Prevalence and impact of cardiovascular metabolic diseases on COVID-19 in China. Clin Res Cardiol. 2020;109(5):531-538. doi:10.1007/s00392-020-01626-9

12. Zhai Y-K, Zhu W-J, Cai Y-L, Sun D-X, Zhao J. Clinical- and cost-effectiveness of telemedicine in type 2 diabetes mellitus: a systematic review and meta-analysis. Medicine (Baltimore). 2014;93(28):e312. doi:10.1097/MD.0000000000000312

13. Tchero H, Kangambega P, Briatte C, Brunet-Houdard S, Retali G-R, Rusch E. Clinical effectiveness of telemedicine in diabetes mellitus: a meta-analysis of 42 randomized controlled trials. Telemed J E Health. 2019;25(7):569-583. doi:10.1089/tmj.2018.0128
14. Ulhaque MS, Bin Zafar A, Ahmed F, Ahmedani MY. Role of 24-hour helpline service in the management of diabetes during the holy month of Ramadan. Cureus. 2020;12(3). doi:10.7759/cureus.7320

15. Khare J, Jindal S. Observational study on effect of lock down due to COVID 19 on glycemic control in patients with diabetes: experience from Central India. Diabetes Metab Syndr. 2020;14(6):1571-1574. doi:10.1016/j.dsx.2020.08.012

Diabetes, Metabolic Syndrome and Obesity: Targets and Therapy

\section{Publish your work in this journal}

Diabetes, Metabolic Syndrome and Obesity: Targets and Therapy is an international, peer-reviewed open-access journal committed to the rapid publication of the latest laboratory and clinical findings in the fields of diabetes, metabolic syndrome and obesity research. Original research, review, case reports, hypothesis formation, expert opinion and commentaries are all considered for publication. The manuscript management system is completely online and includes a very quick and fair peer-review system, which is all easy to use. Visit http://www.dovepress.com/testimonials.php to read real quotes from published authors.

Submit your manuscript here: https://www.dovepress.com/diabetes-metabolic-syndrome-and-obesity-targets-and-therapy-journal 